DOI: $10.17805 /$ trudy.2016.6.8

\title{
ПРОФЕССИОНАЛЬНЫЙ СТАНДАРТ КАК ОСНОВА ФОРМИРОВАНИЯ ПРАКТИКО-ОРИЕНТИРОВАННЫХ ТЕХНОЛОГИЙ В СОВРЕМЕННОМ СОЦИАЛЬНОМ ОБРАЗОВАНИИ (НА ПРИМЕРЕ ДИСЦИПЛИНЫ «СОЦИАЛЬНАЯ КВАЛИМЕТРИЯ, ОЦЕНКА КАЧЕСТВА И СТАНДАРТИЗАЦИЯ СОЦИАЛЬНЫХ УСЛУГ»)
}

\author{
М. Г. Солнышкина \\ (Московский гуманитарный университет)
}

\begin{abstract}
Аннотация: Статья посвящена проблеме применения практикоориентированных технологий в социальном образовании. Выполнена разработка практико-ориентированных заданий по дисциплине «Социальная квалиметрия, оценка качества и стандартизация социальных услуг» на базе профессионального стандарта «Специалист по социальной работе» как элемент системы качества образовательного процесса.

Статья подготовлена на основе доклада автора на ХІІІ Международной научной конференции «Высшее образование для ХХІ века» (8-10 декабря 2016 г., г. Москва).

Ключевые слова: образовательный стандарт; профессиональный стандарт; практико-ориентированные технологии образования; специалист по социальной работе

\section{PROFESSIONAL STANDARD AS THE BASIS FOR PRACTICE-ORIENTED TECHNOLOGIES IN CONTEMPORARY SOCIAL EDUCATION (THE CASE OF THE DISCIPLINE «SOCIAL QUALIMETRY, QUALITY ASSESSMENT AND STANDARDIZATION OF SOCIAL SERVICES»)}

\author{
M. G. Solnyshkina \\ (Moscow University for the Humanities)
}

\begin{abstract}
This article looks at how practice-oriented technologies can be applied in the contemporary social education. As part of assessing the quality of education, we have developed a set of practice-oriented assignments for the course in «Social qualimetry, quality assessment and standardization of social services" for students majoring in Social work.

The article is based on the paper presented at the 13th international research conference "Higher education for the 21st century" (Moscow, December 8-10, 2016).

Keywords: educational standard; professional standard; practice-oriented technologies of education; specialist in social work
\end{abstract}


Качественные изменения, происходящие в высшем социальном образовании, обусловлены, в первую очередь, необходимостью подготовки конкурентоспособного и практико-ориентированного специалиста социальной сферы, обладающего достаточным уровнем компетенции, способного быстро адаптироваться к постоянного меняющемся условиям общественного развития и вызовам современности (Солнышкина, 2015). Практико-ориентированность специалиста формируется на базе деятельностно-компетентностного подхода (Зимняя, 2006), который предполагает:

- конкретизацию способа описания учебных результатов на языке компетентностей;

- разработку инструментов оценивания адекватных объектам контроля;

- согласованность целей и процедур оценивания результатов учебной дисциплины.

Формирование и широкое применение практико-ориентированных технологий современного образования требует разработки практикоориентированных заданий для промежуточного контроля знаний, которые позволяют не только актуализировать изученный материал, но и формируют готовность к профессиональной деятельности в соответствии с требованиям соответствующих профессиональных стандартов (например, при подготовке бакалавров социальной работы базовым является профессиональный стандарт «Специалист по социальной работе», утвержденный приказом министерства труда и социальной защиты РФ № 571 н от 22 сентября 2013 г.). Профессиональный стандарт позволяет вычленить основные характеристики и функции профессии, объемы компетенций, необходимые для качественного выполнения работы (Балакирева, 2013). Так, в соответствии с профессиональным стандартом «Специалист по социальной работе» основной целью данного вида профессиональной деятельности является «оказание помощи отдельным гражданам и социальным группам для предупреждения или преодоления трудной жизненной ситуации посредством предоставления социальных услуг или мер социальной поддержки» (Приказ Министерства ..., Электр. ресурс).

В современных условиях уровень квалификации, который необходим для осуществления определенного вида деятельности, определяется на базе профессиональных стандартов, разработчиками которых являются не только исследовательские и академические структуры, но и профильные работодатели. Так в разработке профессионального стандарта «Специалист по социальной работе» приняли участие ряд профильных работодателей: ГБУ ТЦСО «Новогиреево», «Южнопортовый», «Чертаново»; «Мещанский»; «Ярославский» города Москвы; ГБУ СО МО «Пушкинский 
центр социального обслуживания граждан пожилого возраста и инвалидов» города Пушкино Московской области.

Стратегически правильно рассматривать соответствующий профессиональный стандарт как целевой ориентир подготовки специалиста. Для этого перед разработкой практико-ориентированных заданий по дисциплине «Социальная квалиметрия, оценка качества и стандартизация социальных услуг» нами проведено сравнение умений, знаний, навыков в пределах компетенций, закрепленных за данной дисциплиной (ПК-4 и ПК-13) на основании требований ФГОС с компонентами профессионального стандарта «Специалист по социальной работе» (трудовыми функциями и трудовыми действиями).

Таблица 1. Результаты сравнения умений, знаний, навыков, предусмотренных образовательной программой и требованиями ФГОС, с компонентами профессионального стандарта «Специалист по социальной работе» по профессиональной компетенции ПК-4

\begin{tabular}{|c|c|c|c|}
\hline $\begin{array}{c}\text { Образовательная } \\
\text { программа }\end{array}$ & $\begin{array}{c}\text { Требования ФГОС } \\
3+\end{array}$ & $\begin{array}{c}\text { Положения } \\
\text { профессионального } \\
\text { стандарта }\end{array}$ & $\begin{array}{c}\text { Оценоочные средства } \\
\text { (задания, кейсы, } \\
\text { курсовая работа и } \\
\text { пр.) }\end{array}$ \\
\hline $\begin{array}{c}\text { Учебная } \\
\text { дисциплина }\end{array}$ & Компетенции & $\begin{array}{l}\text { Трудовые функции } \\
\text { Трудовые действия }\end{array}$ & \\
\hline $\begin{array}{c}\text { Социальная ква- } \\
\text { лиметрия, оценка } \\
\text { качества и стандар- } \\
\text { тизация социаль- } \\
\text { ных услуг }\end{array}$ & $\begin{array}{c}\text { Способностью к } \\
\text { осуществлению } \\
\text { оценки качества } \\
\text { социальных услуг, } \\
\text { социального обе-- } \\
\text { спечения и мер } \\
\text { социальной под- } \\
\text { держки на основе } \\
\text { достижений совре- } \\
\text { менной квалиме- } \\
\text { трии и стандарти- } \\
\text { зации; } \\
\text { - Пк-4 }\end{array}$ & $\begin{array}{c}\text { Контроль качества } \\
\text { и эффективности } \\
\text { социального обслу- } \\
\text { живания граждан } \\
\text { и предоставления } \\
\text { мер социальной } \\
\text { поддержки - В/03.7 } \\
\text { Выявление и изме- } \\
\text { рение показателей } \\
\text { качества социаль- } \\
\text { ного обслуживания } \\
\text { и мер социальной } \\
\text { поддержки }\end{array}$ & \multirow[t]{2}{*}{$\begin{array}{c}\text { Вопросы для со- } \\
\text { беседования, } \\
\text { тест, практико- } \\
\text { ориентированные } \\
\text { задания }\end{array}$} \\
\hline Умения & $\begin{array}{c}\text { Определять по- } \\
\text { казатели качества } \\
\text { социальных услуг и } \\
\text { основные принци- } \\
\text { пы стандартизации } \\
\text { социальных услуг }\end{array}$ & $\begin{array}{c}\text { разрабатывать } \\
\text { критерии качества } \\
\text { предоставляемых } \\
\text { услуг и мер соци- } \\
\text { альной поддержки }\end{array}$ & \\
\hline
\end{tabular}




\begin{tabular}{|c|c|c|c|}
\hline Знания & профессиональное & национальные \\
использование спе- & стандарты Россий- \\
циальной терми- & ской Федерации в \\
нологией в области & области социально- \\
стандартизации & го обслуживания \\
& социальных услуг & \\
\hline Навыки & навыками фор- & методы количе- \\
& мирования & ственной оценки \\
& организационно- & качества предо- \\
& управленческих & ставления соци- \\
& решений на базе & альных услуг и мер & \\
& оценки качества и & социальной под- & \\
& стандартизации со- & держки \\
& циальных услуг; & & \\
\hline
\end{tabular}

Также было проведено сравнение умений, знаний, навыков, предусмотренных образовательной программой и требованиями ФГОС с компонентами профессионального стандарта «Специалист по социальной работе» по профессиональной компетенции ПК-13, формирующей исследовательские компетенции специалиста, в первую очередь, в сфере прикладных исследований в практике социальной работы.

Таблица 2. Результаты сравнения умений, знаний, навыков, предусмотренных образовательной программой и требованиями ФГОС с компонентами профессионального стандарта «Специалист по социальной работе»

\begin{tabular}{|c|c|c|c|}
\hline $\begin{array}{c}\text { Образовательная } \\
\text { программа }\end{array}$ & Требования ФГОС 3+ & $\begin{array}{c}\text { Положения } \\
\text { профессионального } \\
\text { стандарта }\end{array}$ & $\begin{array}{c}\text { Оценочные средства } \\
\text { (задания, кейсы, курсо- } \\
\text { вая работа и пр.) }\end{array}$ \\
\hline Учебная дисциплина & Компетенции & $\begin{array}{l}\text { Трудовые функции } \\
\text { Трудовые действия }\end{array}$ & \\
\hline $\begin{array}{c}\text { Социальная квалиме- } \\
\text { трия, оценка качества и } \\
\text { стандартизация соци- } \\
\text { альных услуг }\end{array}$ & $\begin{array}{c}\text { Способностью выявить, } \\
\text { формулировать, разре- } \\
\text { шить проблемы в сфере } \\
\text { социальной работы } \\
\text { на основе проведения } \\
\text { прикладных исследова- } \\
\text { ний, в том числе опроса } \\
\text { и мониторинга, ис- } \\
\text { пользовать полученные } \\
\text { результаты и данные } \\
\text { статистической отчет- } \\
\text { ности для повышения } \\
\text { эффективности соци- } \\
\text { альной работы - ПК-13 }\end{array}$ & $\begin{array}{c}\text { Контроль качества и } \\
\text { эффективности соци- } \\
\text { ального обслуживания } \\
\text { граждан и предостав- } \\
\text { ления мер социальной } \\
\text { поддержки - В/03.7 } \\
\text { Оценка качества со- } \\
\text { циального обслужи- } \\
\text { вания, Выявление и } \\
\text { измерение показателей } \\
\text { эффективности соци- } \\
\text { ального обслуживания }\end{array}$ & $\begin{array}{c}\text { Тест, реше- } \\
\text { ние практико- } \\
\text { ориентированных } \\
\text { задач }\end{array}$ \\
\hline
\end{tabular}




\begin{tabular}{|c|c|c|c|}
\hline Умение & $\begin{array}{c}\text { анализировать и оце- } \\
\text { нивать уровень каче- } \\
\text { ства социальной услуги } \\
\text { в результате исследо- } \\
\text { ваний, } \\
\text { применять экспертные } \\
\text { и мониторинговые ме- } \\
\text { тоды оценках качества } \\
\text { социальных услуг }\end{array}$ & $\begin{array}{c}\text { использовать различ- } \\
\text { ные виды опросов на- } \\
\text { селения и экспертных } \\
\text { опросов, направленных } \\
\text { на выявление каче- } \\
\text { ства и эффективности } \\
\text { предоставляемых услуг } \\
\text { и мер социальной под- } \\
\text { держки }\end{array}$ & \\
\hline Знания & $\begin{array}{c}\text { основные положения } \\
\text { квалиметрии, эволю- } \\
\text { цию ее методов для } \\
\text { исследований каче- } \\
\text { ства услуг социальной } \\
\text { сферы }\end{array}$ & $\begin{array}{c}\text { принципы и правила } \\
\text { проведения опросов } \\
\text { населения и эксперт- } \\
\text { ных опросов, направ- } \\
\text { ленных на выявление } \\
\text { качества и эффектив- } \\
\text { ности предоставляе- } \\
\text { мых услуг и мер соци- } \\
\text { альной поддержки }\end{array}$ & \\
\hline Навыки & $\begin{array}{c}\text { навыками применения } \\
\text { методов исследования } \\
\text { в области социальной } \\
\text { работы для оценки } \\
\text { качества социальных } \\
\text { услуг }\end{array}$ & $\begin{array}{c}\text { анализировать и } \\
\text { оценивать процесс и } \\
\text { результаты реализации } \\
\text { социальных услуг и } \\
\text { социальной поддержки } \\
\text { на индивидуальном } \\
\text { уровне }\end{array}$ & \\
\hline
\end{tabular}

Проделанная работа показала достаточное соответствие структуры компетенций образовательной составляющей (умений, знаний, навыков) и квалификационных требований профессионального стандарта в области трудовой функции В/03.7 «Контролькачества и эффективности социального обслуживания граждан и предоставления мер социальной поддержки» с большим разнообразием трудовых действий. Таким образом можно оценить реальный вклад дисциплины «Социальная квалиметрия, оценка качества и стандартизация социальных услуг» в формирование готовности к конкретной профессиональной деятельности.

Активное формирование профессиональных компетенций на базе решения практико-ориентированных заданий (ситуационные задачи, кейсы, компетентностно-ориентированные задания для промежуточной аттестации студентов) происходит при соблюдении ряда требований к их разработке: ций;

1. отражение в задании важнейших профессиональных компетен-

2. соответствие вида практико-ориентированного задания целям и задачам изучения соответствующей дисциплины;

3. обеспечение формирования не только профессионально-важных личностных качеств, но и технологических умений, которые необходимо проявить в ходе выполнения задания; 
4. возможность определения уровня сформированности профессиональных компетенций студентов как формы промежуточного контроля знаний.

Практико-ориентированные задания имитируют трудовые функции и действия специалиста, создают благоприятную исследовательскую обстановку для подготовки. Например, в дисциплине «Социальная квалиметрия, оценка качества и стандартизация социальных услуг» занятия, моделирующие или отражающие основные аспекты деятельности специалиста социальной работы, помогают студентам изучить организационноправовые основы предоставления социальных услуг в современной социальной сфере; методы, показатели и основные принципы оценки качества социальных услуг; раскрыть сущность и особенности факторов, определяющих качество социальных услуг в обеспечении эффективности деятельности социальных служб; использовать стандартизацию социальных услуг как способ реализации социальных гарантий государства.

Выполнение практико-ориентированных заданий по профессиональной компетенции ПК-4 в соответствии с требованиями ФГОС 3+ (задания $\mathrm{N} 7$ и N 11) позволяет формировать готовность к выполнению трудовой функции B/03.7 «Выявление и измерение показателей качества социального обслуживания и мер социальной поддержки» профессионального стандарта по трудовым действиям, приведенным в таблице 1.

Приведем примеры этих заданий.

Задание № 7:

В реабилитационном центре для детей-инвалидов разрабатываются мероприятия по повышению качества услуг. В связи с эти необходимо скомплектовать документы, в соответствии с которыми функционирует данное учреждение. Какие это документы? На какие еще факторы необходимо обратить внимание? На основе ГОСТ Р 52496-2005 «Социальное обслуживание населения. Контроль качества социальных услуг» дайте ваши профессиональные предложения и спроектируйте мероприятия, реализующие факторы качества медико-социальных и социальнореабилитационных услуг.

Задание № 11:

В настоящее время в регионах разрабатываются стандарты и регламенты социальных услуг на базе учреждений социального обслуживания, основанные на процессном подходе. Дайте ваши профессиональные предложения по разработке процессного подхода в центре социальной защиты семьи и детей и выделите: А) основные процессы; Б) обеспечивающие процессы; В) процессы менеджмента на основании следующего критерия классификации: степень влияния на производство социальных услуг.

Выполнение практико-ориентированных заданий по профессио- 
нальной компетенции ПК-13 в соответствии с Требованиями ФГОС 3+ (задания № 2 и N 6) позволяет формировать готовность к выполнению трудовой функции В/03.7 «Выявление и измерение показателей качества социального обслуживания и мер социальной поддержки» профессионального стандарта по трудовым действиям, приведенным в Таблице 2.

Приведем примеры этих заданий.

Задание № 2 .

Ситуация: Предположим, что вы являетесь руководителем Центра социального обслуживания населения. Для формирования Руководства по качеству учреждения Вам необходимо провести социологическое исследование «Удовлетворенность доступностью и качеством социальных услуг в центре социального обслуживания населения». Объектом исследования являются получатели социальных услуг в Центре социального обслуживания. Предмет исследования: удовлетворенность получателей социальных услуг качеством оказываемой помощи. Цель исследования выявить удовлетворенность качеством социальных услуг.

Вопросы: Раскройте задачи исследования. Определите научную и практическую ценность решаемых исследовательских задач с позиций формирования политики качества учреждения.

Задание № 6:

Вам как бакалавру социальной работы необходимо и провести цикл занятий с пожилыми людьми в Доме ветеранов г. Железнодорожный по вопросам здорового образа жизни (ЗОЖ). Вопросы:

1. Какие аспекты ЗОЖ наиболее актуальны в этом возрасте?

2. Достижениями научных исследований в каких областях знаний Вы будете руководствоваться при формулировке конкретных рекомендаций по сохранению и укреплению здоровья, профилактике старения?

Апробация практико-ориентированных заданий по данной дисциплине показала реальную возможность определения уровня сформированности профессиональных компетенций студентов в процессе промежуточного контроля знаний. Разработка практико-ориентированных заданий по дисциплине «Социальная квалиметрия, оценка качества и стандартизация социальных услуг» будет продолжаться, также будут развиваться и виды практико-ориентированных заданий (в настоящее время 70\% заданий представлено ситуационными задачами). Многообразие форм заданий будет дополнено, прежде всего, анализом профессионального стандарта «Специалист по социальной работе», составлением сравнительных характеристик социальных услуг, прогнозированием процессов и сценариев развития конкретных ситуаций социального риска, обуславливающих необходимость социального обслуживания. 


\section{СПИСОК ЛИТЕРАТУРЫ}

Балакирева, Э. В. (2013) Профессиональный стандарт как ориентир разработки подходов к оценке качества профессиональной подготовки специалистов в вузе // Известия Российского государственного педагогического университета им. А. И. Герцена. №. 158. С. 86-95.

Зимняя, И. А. (2006) Компетентностный подход. Каково его место в современной системе современных подходов к проблеме образования (теоретико-методологический аспект) // Высшее образование сегодня. №8. C. 20-26.

Солнышкина, М. Г. (2015) Профессиональная компетентность работников и руководителей социальных организаций в аспекте формирования личностных и социальных компетенций бакалавров социальной работы // Высшее образование для XXI века: XII Международная на-учная конференция. Москва, 3-5 декабря 2015 г. : Доклады и материалы. Секция 2. Социология образования / отв. ред. Н.А. Селиверстова. М. : Изд-во Моск. гуманит. ун-та. 93 с. С. 65-69.

Приказ Министерства труда и социальной защиты населения от 22 октября 2013 г. № 571 н «Об утверждении профессионального стандарта «Специалист по социальной работе» [Электронный ресурс] // Гарант. URL: http://base.garant.ru/70535562/ (дата обращения: 19.09.2016).

Дата поступления: 15.11.2016 г.

Солнышкина Марина Георгиевна - доктор социологических наук, профессор, профессор кафедры социологии Московского гуманитарного университета. Адрес: 111395, Россия, г. Москва, ул. Юности, д. 5. Тел.: +7 (906) 074-35-49. Эл. адрес: solny2001@mail.ru

Solnyshkina Marina Georgievna, Doctor of Sociology, Professor, Department of Sociology of the Moscow University for the Humanities. Postal address: 5 Yunosti St., 111395 Moscow, Russian Federation. Tel.: +7 (906) 07435-49. E-mail: solny2001@mail.ru

\section{Для циитирования:}

Солнышкина М. Г. Профессиональный стандарт как основа формирования практико-ориентированных технологий в современном социальном образовании (на примере дисциплины «Социальная квалиметрия, оценка качества и стандартизация социальных услуг») [Электронный ресурс] // Научные труды Московского гуманитарного университета. 2016, № 6. URL: http://journals.mosgu.ru/trudy/article/view/380 (дата обращения: дд.мм.гг.). 